\title{
Emergence of bottom-up saliency in a spiking model of $\mathrm{V} 1$
}

Botond Szatmáry*, Micah Richer, Jayram Moorkanikara Nageswaran, Csaba Petre, Filip Piekniewski, Sach Sokol, Eugene M Izhikevich

From Twenty Second Annual Computational Neuroscience Meeting: CNS*2013

Paris, France. 13-18 July 2013

We present anatomically detailed spiking model of the parvo and magno pathways of the retina, primary visual cortex (V1), and superior colliculus (SC) to enable active saccades. Due to STDP and visual experience, the model shows the emergence of a saliency map, resulting in the perceptual behavior of bottom-up (pop-out) attention.
In contrast to previous models proposed to explain pop-out based attention for simple features (e.g., saliency map hypothesis of [1]), where feature selectivity and inhibitory mechanisms between similar features are pre-wired, connectivity in our spiking model is neither pre-wired nor are neurons pre-labeled,
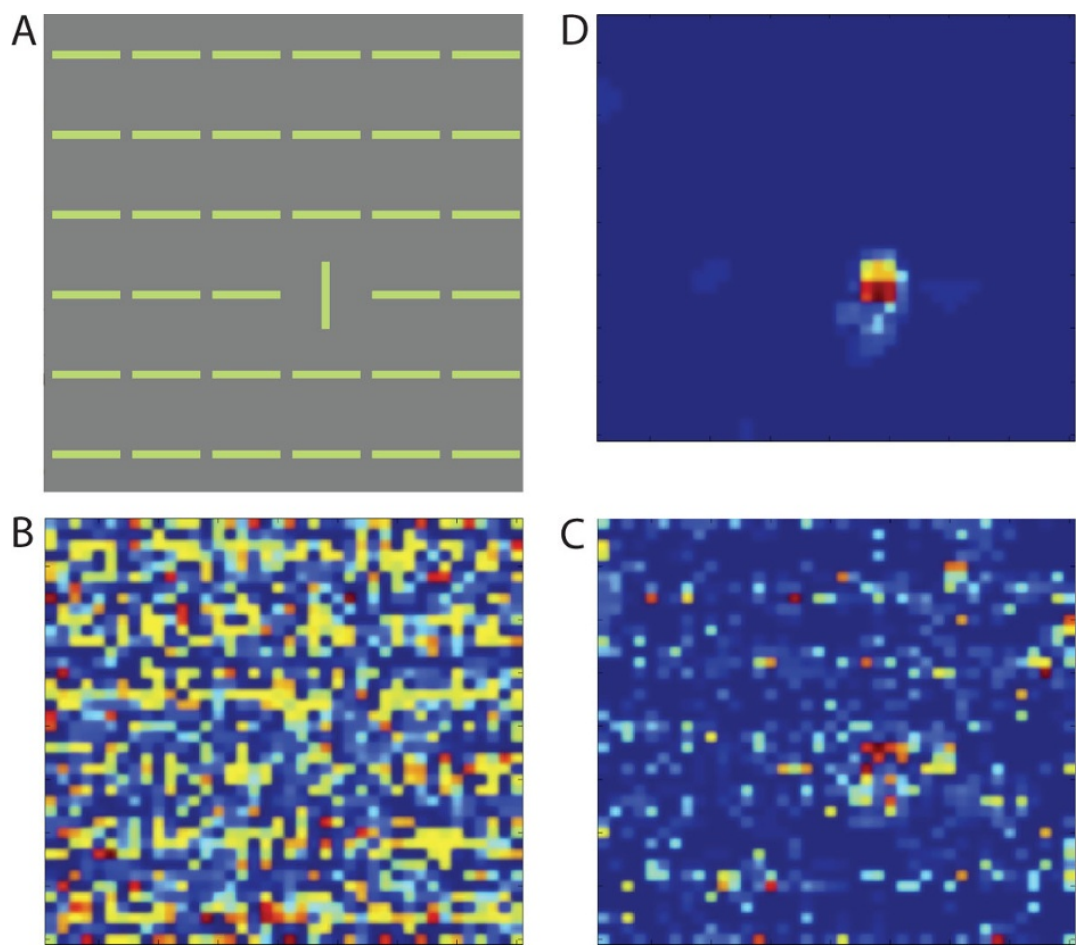

Figure 1 A. Input image; B. V1 layer 2/3 activity without long-range inhibition; C. V1 layer 2/3 activity with long-range inhibition; D. Superior colliculus activity that directly drives the saccadic mechanism. Activity is averaged over two seconds.

\footnotetext{
*Correspondence: szatmary@braincorporation.com
}

Brain Corporation, San Diego, CA 92121, USA 
but feature selectivity and pop-out behavior still emerges.

Projections between cell types in the V1 model (L4 and L2/3) are in agreement with anatomical data. Both excitatory and inhibitory synapses are subject to different forms of STDP. These plasticity mechanisms and exposure to rich natural visual stimuli lead to (i) neuronal responses similar to those recorded in vivo, (ii - parvo) formation in color selective cells, and (iii - magno) formation of simple and complex cells covering a broad range of orientations and spatial frequencies.

Pop-out mechanism is mediated by modifying the activity in layer $2 / 3$ with long-range effective inhibition using a narrow form of STDP, which selectively picks up short temporal correlations between neurons responding to similar features but depresses ignores neurons responding to different features. Stronger within-feature long-range inhibition dampens the population response to features that are abundant in the input, but allows strong response to salient input features. The activity of $\mathrm{V} 1$ drives the $\mathrm{SC}$, resulting in pop-out saccades. (The SC model is presented in a separate submission.)

The model connects electrophysiology (spiking activity) and perception, and it explains animal behavior in a variety of standard pop-out tasks.

Neurons responding to vertical features will receive strong inhibition from other vertical neurons, therefore weakening their response, while response triggered by the single horizontal bar remains strong.

Published: 8 July 2013

\section{Reference}

1. Itti $\mathrm{L}$, Koch C: Computational modelling of visual attention. Nature Reviews Neuroscience 2001, 2(3):194-203.

doi:10.1186/1471-2202-14-S1-P183

Cite this article as: Szatmáry et al:: Emergence of bottom-up saliency in a spiking model of V1. BMC Neuroscience 2013 14(Suppl 1):P183.
Submit your next manuscript to BioMed Central and take full advantage of:

- Convenient online submission

- Thorough peer review

- No space constraints or color figure charges

- Immediate publication on acceptance

- Inclusion in PubMed, CAS, Scopus and Google Scholar

- Research which is freely available for redistribution

Submit your manuscript at www.biomedcentral.com/submit 